\title{
BEING A POSTGRADUATE WOMAN: RELATIONSHIPS, RESPONSIBILITIES AND RESILIENCY
}

\section{Guin Lourens}

\section{INTRODUCTION}

Female students face particular constraints when pursuing postgraduate degrees. The challenges they may face regarding the timing of their studies in relation to lifeline events such as childbearing years and the constant tension between academic and family responsibilities is a reality across the world. Therefore, women's education is shaped by personal and structural gendered forces, including family, economic and workplace issues. The culmination of such studies I have found to be a careeraltering experience, which develops personal resiliency, but tests your reserves for relationships and responsibilities. This chapter discusses the educational pathways of postgraduate female students in higher education, possible barriers and sources of support.

\section{GENDER AND EDUCATION}

Gender issues are not unique in the South African context and are located in history and in the heady cultural mix of a country that holds a population rich in ethnic diversity with a wide range of cultures, languages and religious beliefs. The focus at most universities in South Africa prior to 1994 was the struggle against the apartheid regime and racial inequality. The gender inequality struggle, however, gained momentum during this time to set the agenda for women's issues and champion women's liberation. The socalled academic arm of the women's movement took this articulation of a feminist agenda into the universities and created space for debate (Gouws 2012). Gender mainstreaming as part of South Africa's National Gender Policy has given rise to commonplace phrases such as gender equality, women's empowerment and gender transformation. This process should question policy to rectify gender disparities, but success has been hampered by the masculinised 
organisational cultures and deeply patriarchal institutions in which women's interests are in some cases met with hostility (Gouws 2010).

Education for women is regarded as fundamental to the empowerment of women and to achieve gender equality. The South African government has produced a number of policies and equality legislation in pursuit of women's empowerment. For instance, the Constitution includes Section 9 which promotes equality for all persons and freedom from discrimination and the Employment Equity Act, No 55 (1998), which strives to achieve equity in the workplace by promoting fair treatment in employment. The African Union (AU) declared 2015 as the Year of Women Empowerment and Development. The declaration is a display of $\mathrm{AU}^{\prime}$ s renewed political commitment and support for the women's empowerment and the gender equality agenda. So while other parts of the world may have moved on from focussing on the disadvantages and difficulties of women pursuing post-basic degree programmes (Acker 2014), the advocacy for the female agenda still rages on in Africa.

Statistics South Africa $(2010)$ reveals a social profile in the country of fractured families, rising numbers of children orphaned by HIV and AIDS in child-headed households or being raised by female relatives, and single motherhood as a widespread norm. Gender-based violence, sexual harassment and assault, as well as the objectification of women are still commonplace, as reported in the status of women and girls in SA report (ONE 2015). Most racial and ethnic groups in South Africa, historically segregated, have distinct cultural long-standing beliefs concerning gender roles. Some are based on the premise that women are less important or deserving of power than men and that women's contributions to society should be sanctioned by men. This includes some traditional Afrikaner and African social organisations which are male-centred and dominated. Urban and rural cultures continue to differ, but a generational shift in cultural expression towards a more interracial, multi-ethnic, enlightened, inclusive and cosmopolitan slant is slowly weaving a new South African social tapestry (StatsSA 2016).

Gender has shaping effects in the South African societal context and to a large extent many of us simply live the subtle subordination of women. A continued gendered domestic division of labour and obligations leaves women students remaining responsible, as it was in my case, for most of the routine physical and emotional care for children (Leonard, Becker \& Coate 2010). Housework includes caring for men as husbands or partners, housekeeping, shopping, preparing meals and laundry, and cleaning up. Motherhood is a combination of seeing to children's nutritional, hygiene, health, environmental, as well as social needs and relevant educative activities. Acker (1994), a seminal author on gendered education, found that married female 
students - especially those with children - face impossible demands on their time and energy, with which I would concur. They also experience the expectation that the husband/male partner's career will have priority in case of conflict. Family work for female students is not only confined to housework and childcare. It also includes care for the elderly, disabled, fostered or orphaned children, working on maintenance of kinship ties and spending quality time with partners and significant others. Other constraints encountered by female students as found in literature include domestic problems, concerns about suitable childcare, less freedom to travel than men, a lack of fair access for women to and unresponsiveness of academic institutions (Evetts 2014), exorbitant study fee costs against a backdrop of limited financial stability and no forthcoming financial aid or suitable accommodation near campus, resulting in gruelling commutes (Murray 2014). Authors such as Acker (2014) ask if higher education is fair to women in finding a path towards their academic aspirations.

In the World Economic Forum's Global Gender Gap Report (2013), South Africa ranks well in terms of women's political empowerment, economic participation and opportunity, yet the status of women in the country remains complicated. The higher education levels and qualifications, the more likely a woman is to be employed while studying. Work-life articulation therefore requires more attention. Career success and studies are affected as even full-time employed women usually retain the major responsibility for caring and domestic work (Crompton \& Lyonette 2011).

Nevertheless, women as a group is a collection of individuals making choices about taking options, seizing chances and seeking opportunities. Access to better quality secondary education and tertiary education opportunities for previously marginalised women in South Africa has increased (ONE 2015). This has been partly enabled, I believe, by dedicated academic bursaries for women, something I have been involved in and benefitted from myself. It is encouraging to note a $42 \%$ to $58 \%$ female versus male postgraduate trend in South Africa (Cloete, Mouton \& Sheppard 2015), with a significant annual growth in female students.

Female postgraduate students are by no means a homogenous group. When this group is viewed through a South African lens, we see a kaleidoscope of variety in terms of age, background, urban or rural origin, economic, work and family responsibilities. However, a discourse on gender equity and activism in higher education academic communities would benefit a broad base of women in this country. There is a difference in having substantive and procedural equality in the gendered nature of citizenship, and living it. The way in which rights and gender are constructed in discourse and implemented in reality, makes the difference in the complexities of women's lives (Gouws 2005). I have written this chapter from my 


\section{POSTGRADUATE STUDY IN SOUTH AFRICA}

own narrative perspective as a part-time postgraduate student, working full-time with demanding work and family responsibilities, while remaining cognisant of the multilayered gendered perspectives that may require individual exploration.

\section{DEVELOPING RESILIENCE}

According to Dole (2014) resilience, which is conceptualised as a group of traits enabling individuals to withstand and to recover quickly from adversity, differs from academic resilience. Academic resilience is defined as "the process and results that are part of the life story of an individual who has been academically successful, despite obstacles that prevent the majority of others with the same background from succeeding" (p. 144). Your postgraduate journey as a female student will require a fluid process of acquiring resilient qualities which strengthen over time'.

Women's career aspirations are often influenced by the fact that they are female. Gender-specific notions of pursuing an education are socio-culturally and psychologically deeply rooted in traditional values and traditions. The paths for simultaneous career and professional development for a woman may seem unclear and to combine the two, exceptional intrinsic motivation and determination to overcome obstacles is needed (Bhalulesesa 2010). Dole (2014) identifies protective factors that contribute to resiliency in order to overcome the barriers women encounter on their paths to academic success. The factors include strong personal characteristics, such as perseverance and positive relationships in the family and community. These serve as sources of support to ameliorate the effects of difficulties.

In my predominantly female profession in South Africa, only around one percent of professionals obtain a doctorate opposed to 23,54\% of academics holding PhDs (Van Rooyen, Ricks \& Morton 2012). These are the type of statistics which, for me, can cultivate a steely determination to beat the odds and foster goal directedness. As in the poem, The Road Not Taken by Robert Frost, which is often read at graduations, I can relate to the doubt and apprehension of taking the route of postgraduate studies less travelled by my female colleagues. It has, however, made all the difference in career self-actualisation. I would regard a strong sense of self-belief as a vital ingredient to success.

1 Also see Chapter 5 where Bella Vilakazi writes about the lived experience of developing resilience. 


\section{THE ROLE OF FAMILY AND FRIENDS}

The postgraduate student does not study in isolation. Family and friends have to put up with a lot while you are working on your research. Even when not working late or over weekends one may often be pre-occupied with your study in time that they may view as belonging to them. As Cryer (2006) suggests, it is useful to tell family and friends what to expect from the outset, negotiate ways of meeting their needs as well as yours, and get their support (Cryer 2006). Family support appears to be one of the most important factors in succeeding as a student (Dole 2014), and it is therefore essential to get family and significant others on board.

Family responsibilities are often seen as an inseparable commitment around which a career must be built. The need to fulfil typical caretaking roles can be a distraction for self-actualisation in postgraduate studies. When families and academic communities both value the dual roles that having a family and an academic pursuit entail, women are better able to balance their roles and cope with the stress of postgraduate studies (Bhalalusesa 2010). I would consider work and family demands realistically when setting deadlines for completing a degree.

Role conflict or the simultaneous, incompatible demands of family and being a student can lead to role overload (Rowlands 2010). Achieving a balance between social roles, relationships and responsibilities and the interface between that and academic expectations of the postgraduate student often require some support with domestic and childcare duties. Women in families are more likely to be called upon and expected to help with extended family crises involving siblings or the care of aging parents. These types of commitments, although they inevitably caught me off guard, need to be factored into study plans. ${ }^{2}$

I concluded my doctoral studies while working full-time as a manager in the health sector and doing part-time postgraduate lecturing at a distant university. In addition, I had a husband and two school-going children. I would not have been able to complete my studies without the support and encouragement of my close female friends. If you have young children, you can ask your network of friends who stay at home to help you with transporting children and play-dates when you need to focus on your studies. I will always be indebted to these selfless friends. Mobilising grandparents to assist with childcare is helpful, but not always geographically possible. Planning for more than one child to go on play-dates with friends at the

2 See also Chapter 12 by Langutani Masehela that is focussed on the notion of Ubuntu, as well as Soryaya Abdulatief's chapter on dealing with first-generation challenges. 
same time can also give you pockets of uninterrupted time, though you would need to reciprocate these favours.

As a working mother with multiple commitments, you may not always be at liberty to put your studies first. Sometimes you may need to first focus on your work and family commitments and then work on your studies at night when your family is asleep, or get up early if you are a morning person. Similarly, the best use of time must be made when family members are not at home over weekends. Prioritising, sharing responsibilities with a partner, procuring all the labour-saving devices you can afford (Hart 1997), as well as hiring domestic assistance may help you achieve your academic goals. Having a system to organise the family diary and an effective household filing system can help reduce chaos. Organising menus, buying in bulk and preparing meals in advance can be useful. Reducing domestic clutter goes a long way to enable an environment conducive to study completion. Having administrative support at home can also help you make progress. Outsourced administrative support services are available to create order in your research filing system or study space. Assistance is also available for transcription, statistical analysis, as well as proofreading and formatting of your thesis according to the university guidelines. Seeking out and engaging with such support services, as I did, may be invaluable in surviving and succeeding your postgraduate studies.

\section{THE INFLUENCE OF EMOTIONAL PRESSURES ON FEMALE POSTGRADUATE STUDENTS}

Complex emotions associated with balancing family and scholarly commitments and having to choose between "head" and "heart" are experienced. Family relationships can be both places of solace and generators of stress in terms of lost time and opportunities. Conflicted feelings can emerge over the impact of studies on the family and feelings of guilt over prioritising your own needs over children, partners and extended family or friends. These emotional pressures can be overwhelming and erode at one's confidence, resilience and productivity. Sustained tensions between the two key emotional flashpoints of study and family relationships may have a debilitating impact on your studies (Aitchison \& Mowbray 2013).

The research process itself comes with patterns of emotions and while each stage of the research process is inclined to start in a positive way, inevitably obstacles arise. Each stage from planning, to data collection, to analysis, to reporting and even publication has its own set of difficulties, sending one on a tumultuous emotional passage. The researcher experiences a changing emotional state over time, something I have experienced myself. As an emotive woman, I can personally relate 
to the dejection of having periods of writing block, getting corrections and rejections, and struggling with delays. Persistence and problem solving are tested to the utmost. Sometimes, you may experience bouts of energy, but these should be treated with care. Harnessing the energy can be productive, while on the other hand, it can fire an emotional war of scorching proportions and lead to burnout. I found that these short bursts of energy gave momentum in writing my thesis, but had to be countered by making room for rest and limiting sleep deprivation. It is understandable to me that the ways women knowledge workers cope usually involve working harder and sleeping less, but it must be questioned to what extent this can be considered empowering (Acker \& Armenti 2004).

Connecting with my personal energisers such as poetry and music helped drive creativity in the writing process. Amidst the domestic clatter, consciously creating personal spaces for sanctuary, rest and relaxation in my home allowed for some revitalisation. Other approaches to deal with the tension of postgraduate study include yoga, relaxation exercises, taking time out, meditation, prayer and writing a daily gratitude journal. Journaling can be useful to ventilate your feelings and thoughts (Ban Breathnach 2005) or mind-map your concepts. The idea of morning pages, which is free writing of a couple of pages about whatever comes to mind first thing in the morning, can stimulate creativity (Cameron 1995). Flores (2015) suggests seeking out sources of inspiration and feedback, saying no to distracting activities, not neglecting your physical health, budgeting some money for time away from your studies, fighting perfectionism and having a supportive friend or family member as ways of counteracting emotional pressures. Join supportive networks with other students ${ }^{3}$.

\section{WORK ARRANGEMENTS}

Despite the changing demographics of the South African workforce which includes more women, driven by the economical need and employment equity legislation, flexible work options are not common. The South African workplace is still largely inflexible for the working female student. The Labour Relations Act (Act 66 of 1995) does not single out flexible workers, but includes all employees that work more than 24 hours per month. There is, however, a swell rising in the country towards working from home, flexible hours with more productive time and less time spent in traffic. Change is very slow and most women still have to comply with rigid office hours, full responsibilities and commuting while doing postgraduate studies. The Centre

3 See chapters 16 and 17 in this book for discussions on the benefits of such interactions. 
for Economics and Business Research, Citrix and Productivity SA concur that flexible working hours would be beneficial to productivity, the economy, for employees who are parents and reduce the risk of burnout (Leshoro 2015). Flexibility to adjust work time or workplace when your study needs are in conflict with your work schedule would allow female post graduate students to function better.

Flexible work arrangements are ideal while conducting postgraduate studies. Working and studying while managing a home life is challenging and tiring, but can also be interesting and rewarding. Seen in a positive light, the studies do add to the mental stimulation a job offers, personal development and furthering your career in numerous ways. A workplace which provides research opportunities for women, and especially one which allocates dedicated protected time for postgraduate research (White 2004), is conducive to successful studies. It is not always possible to get study leave or a sabbatical. It might be viable to sacrifice some of your annual leave, as I did, to get ahead with research activities and writing. If you are serious about completing your studies, this kind of sacrifice is well worth it.

\section{BUILDING A SOCIAL SUPPORT SYSTEM}

Isolation is identified as one of the key factors associated with non-completion of postgraduate studies (Mouton 2009). Concluding a thesis is often an independent and lonely journey. White (2004) cites isolation, lack of confidence, minimal mentoring, limited informal networking, inflexible and unsupportive university environments, as well as negative attitudes towards women pursuing postgraduate studies as reasons for not completing research degrees. As a woman you may grapple with a lack of understanding amongst family and friends for your drive to attain a postgraduate degree and this may compound the feeling of the loneliness.

Loneliness can, however, be cultivated to allow your thoughts to grow. It was often in these lonely spaces where I found the time to reflect on my doctoral work, interrogate my aims to reach increased insight, and develop the intervention strategy of my study. Graduate support groups, friends and partners can be sources of impetus to counter personal and academic pressures that may cause stress and anxiety. Linking up with like-minded women on the same journey has the potential to propel you forward. Correspondence with female authors in the field of your study can also be inspiring. Emulating leading female academics and finding female mentors can help you to transition the thresholds of postgraduate study completion. I belong to a local business network which meets weekly and I drew a great deal of inspiration from the other professional women in the network who are successfully combining career and family. 
Social networks can be instrumental for women in providing emotional and informational assistance while studying. Actively seeking strong social network ties or postgraduate study support groups can impact on meeting your psychosocial needs and developing resilience. This can take different forms, depending on personal preference, and can include physically meeting on a regular basis, an email discussion or online group, or even a mobile phone based group.

Social and academic integration can help to ensure academic postgraduate success (Koen 2007). This integration can be achieved by means of joining quality academic support groups for connected learning and developing strong student to student relationships. I joined a PhD support group late in my doctoral studies but even then it gave me that final push to reach the finishing line. It was beneficial to network with other female health professionals and take some courage away from each session. Joining such a group will allow you to benefit from the shared experiences, lessons learned, process guidance and the collegiality which these groups offer. It fuelled my ambition and drive to finish ${ }^{4}$.

\section{INSTITUTIONAL SERVICES AND SUPPORT}

Generic support provided by higher education institutions may not be suited to the specific support needs of the postgraduate woman, especially those whom study part-time and/or at a distance. Institutional administrative support can also make a difference in your success. Universities that offer flexible options for even mundane aspects such as parking disc collection, or registration options and accurate information on fees, bursaries and thesis requirements are much easier to navigate. For a working postgraduate student, flexibility in the format or structure of the course is key due to potential time constraints during office hours.

Seek out a higher education environment which includes tailored support, collegiality with other postgraduate women and an acknowledgement of stresses linked to gender. Acknowledgement of the duality of demands most women face in the journey towards achieving doctoral level studies could be insightful in navigating the pursuit of postgraduate study through enhanced access to appropriate educational provisions and services (Grenier \& Burke 2008). Most universities offer free counselling services to students. A sounding board may be required if you grapple with issues of being a professional career woman, wife, caretaker, mother, daughter, sister and student with an academic identity. With progress towards completion of postgraduate qualifications comes consideration of career path changes. I view

4 Also see Part 5 of this book that explores postgraduate study as a social practice. 
student counselling and support services positively, as they hold the possibility of access to advanced career coaching.

Obers (2014) describes mentoring as a supportive, nurturing process of providing psycho-social support and coaching to facilitate growth. Mentoring programmes can address social connectedness. It is, however, not always optimally utilised in higher education as a transformation strategy for building women's self-esteem in academic environments and developing a professional network structure of women academics.

Choosing a university and supervisor wisely can have a determining impact on your ultimate success. Support and facilities should be of such a calibre that you would want to invest your money and your valuable time there. The peer support and academic development culture is something to scrutinise. The needs of women for a social learning environment, comfortable postgraduate learning spaces, and support in the development of academic research and writing skills should influence choice of institution (Whisker 2008).

A healthy supervisor-student relationship is characterised by mutual respect (McMillan 2002), dignity, courtesy and honesty (Cryer 2006). Boundaries in terms of privacy and personal space may need to be set in terms of accessibility to each other. In negotiating deadlines, disclosure upfront about your responsibilities at home and work can be done without burdening your supervisor with all the personal challenges you face while juggling to learn. Discuss demands on both parties' time and how you feel about after hours' contact. Well-defined boundaries help both student and supervisor to be clear about where they stand and encourage clarity and progress. I found getting into a rhythm of monthly meetings with my supervisor conducive to momentum. We opted for no after hours' contact, but I did most of the academic work at night, and sent electronic correspondence or made telephonic contact during office hours.

Among the interventions that may assist more women to enrol and successfully complete higher degrees, White (2004) lists excellent information, financial support, flexibility in study mode to include full-time to part-time transition, active encouragement from lecturers, mentoring schemes and a research culture to facilitate postgraduate networking and student support groups. Policy innovations should move from a homogenous approach. Innovation should stem from acknowledging that women are increasingly "time poor" and helping them cope with this by new modes of working and considering what to do to enable women to study. A postgraduate study journey gains emotional, intellectual and vocational ground for female students but requires careful consideration in terms of the institutional approach (Leonard, Becker, \& Coate 2010). 


\section{TIME MANAGEMENT}

Writing up a study from the proposal phase through to the individual chapters and finally the completed thesis requires substantial blocks of time - time for preparation, reflection, searching for relevant information, reading, writing, data gathering and analysis, and meetings with your supervisor. I find the theory of time management fascinating and useful but often obliterated by reality. It is often more realistic to use short bits of available time daily than trying to find several hours at once.

Time management in postgraduate studies is marked by being realistic about what is involved and about the volume of work, as well as what is humanly possible within your multiple responsibilities, and planning for some periods of rest and recreation. Life events may force you to modify your plan, and through this process, I had to learn the lessons of flexibility, acceptance and self-kindness. Talking to other postgraduate students with similar family, work and/or study responsibilities in terms of how they structure their time may help set realistic goals for completion with clear, concrete outcomes. Dividing up tasks and activities, using a to-do list for each section or applying time management software can be helpful approaches. It is rewarding to keep track of your academic progress and there are some electronic software applications geared towards this end.

\section{CONCLUSION}

Unfortunately, there is a dearth of literature on the experiences of female postgraduate students in the South African context. The value of this chapter lies in its contribution to the emerging debate in this field in South Africa and the implications for our society and academic institutions. The need for all stakeholders to play an active role in detailed planning for facilitation of female postgraduate teaching and learning to promote academic success is apparent.

The dual worlds of research writing and juggling job and family demands are often challenging for female postgraduate students. The need to be self-directed in learning and passionate about your topic to find the courage to continue and sustain academic impetus is evident. Intrinsic motivation, as well as developing selfconfidence as a student, and tenacity in commitment to your studies can contribute to your eventual success.

When you finally come to the end of a postgraduate study, you may vacillate between elation and a sense of anti-climax. As you re-shift your focus from your thesis, take a moment to reflect. There is a host of transferable skills you have learned in terms of problem solving, project mapping and management, planning, balancing priorities, time management, communicating and presenting. Find creative ways of sharing 


\section{POSTGRADUATE STUDY IN SOUTH AFRICA}

your life lessons and approaches with other women who are headed on this road. Encourage other women with academic ambitions - it is now your time to be a role model and mentor.

\section{REFERENCES}

Acker, S. (2014). A foot in the revolving door? Women academics in lower middle management. Higher Education Research and Development, 33(1):73-85. http://dx.doi.org/10.1080/07294360.2013.864615

Acker, S. (1994). Gendered education. Buckingham, UK: Open University Press.

Acker, S., \& Piper, D. (1987). Is higher education fair to women? Surrey, UK: Society for Research in Higher Education.

Acker, S., \& Armenti, C. (2004). Sleepless in Academia. Gender and Education, 16(1):3-24. http://dx.doi.org/10.1080/0954025032000170309

Aitchison, C., \& Mowbray, S. (2013). Doctoral women: Managing emotions, managing doctoral studies. Teaching in Higher Education, 18(8):859-870.

http://dx.doi.org/10.1080/13562517.2013.827642

Ban Breathnach, S. (2005). Simple abundance. New York, USA: Bantam Books.

Bhalulesesa, E. (2010). Women's career and professional development: Experiences and challenges. Gender and Education, 10(1):21-33. http://dx.doi.org/10.1080/09540259821078

Cameron, J. (1995). The artist's way: A course in discovering and recovering your creative self. London, UK: Pan Books.

Cloete, N., Mouton, J., \& Sheppard, C. 2015. Doctoral Education in South Africa: Policy, Discourse and Data. Cape Town, South Africa: African Minds.

Crompton, R., \& Lyonette, C. (2011). Women's career success and work-life adaptions in the accounting and medical professions in Britain. Gender, Work and Organization, 18(2):231-254. http://dx.doi.org/10.11 1 1//.1468-0432.2009.0051 1.x

Cryer, P. (2006). The researcher student's guide to success (3rd ed.). New York, USA: Open University Press.

Dole, S. (2014). Voices of resilience: Successful Jamaican women educators. Journal of Ethnographic and Qualitative Research, 8:144-156.

Evetts, J. (2014). Women and Career; Themes and issues in advanced industrial societies. New York, USA: Routledge.

Flores, L.A. (2015). Dissertation finish line. Available online at

https://www.insidehighered.com/advice/2015/04/10/easy-bow-reach-phd-dissertation-finishline?hootPostID = eaa9d82861aa00a151c9cf0ec8fbddddd

Gouws, A. (2005). (Un)thinking citizenship. Feminist debates in contemporary South Africa. Aldershot, UK: Ashgate.

Gouws, A. (2010). Feminism in South Africa today: Have we lost the praxis? Agenda, 24(83):13-23. 
Gouws, A. (2012). Reflections on being a feminist academic/academic feminism in South Africa. Equality, Diversity and Inclusion: An International Journal, 31 (5/6)"526-541.

Grenier, R., \& Burke, M.C. (2008). No margin for error: A study of two women balancing motherhood and PhD studies. The Qualitative Report, 13(4):581-604.

Hart, M. (1997). Mothers at work. London, UK: Michael 'O Mara Books.

Koen, C. (2007). Postgraduate student retention and success: A South African case study. Cape Town, South Africa: HSRC Press.

Leonard, D., Becker, R., \& Coate, K. (2010). Continuing professional and career development: The doctoral experience of education alumni at a UK university. Studies in Continuing Education, 26(3):369-385. http://dx.doi.org/10.1080/0158037042000265953

Leshoro, D. (2015). Most South Africans would love flexible working hours. SABC News. 27 August.

McMillan, W. (2002). The postgraduate student's survival guide. Bellville, South Africa: University of the Western Cape.

Mabokela, R.O. (Ed.) (2007). Soaring beyond boundaries: Women breaking educational barriers in traditional societies. Rotterdam, Netherlands: Sense Publishers.

Murray, M. (2014). Factors affecting student dropout rates at the University of KwaZulu-Natal. South African Journal of Science, 1 10(1 1/12):1-6. http://dx.doi.org/10.1590/sajs.2014/20140008

Mouton, J. (2009). How to succeed in your Master's \& doctoral studies: A South African guide and resource book. Pretoria, South Africa: Van Schaik.

Obers, N. (2014). Career success for women academics in higher education: Choices and challenges. South African Journal of Higher Education, 28(3):1 107-1122.

ONE. (2015). Status of women and girls in SA. Available online at https://s3.amazonaws. com/one.org/pdfs/Status-of-women-and-girls-in-South-Africa-2015.pdf

Rowlands, S. (2010). Non-traditional students: The impact of role strain on their identity. (Unpublished Master's dissertation). Department of Workforce Education and Development in the Graduate School, Southern Illinois University, Carbondale, IL, USA.

Statistics South Africa. (2010). Social profile of South Africa. Pretoria, South Africa. Available online at www.statssa.gov.za

Statistics South Africa. (2016). Mapping diversity:an exploration of our social tapestry. Pretoria, South Africa. Available online at www.statssa.gov.za

Van Rooyen, D., Ricks, E., \& Morton, D. (2014). Status of research related activities of South Africa's University Nursing schools. Trends in Nursing, 1 (1):29. http://dx.doi.org/10.14804/1-1-29 http://dx.doi.org/10.14804/1-1-30

White, K. (2004). The leaking pipeline: Women postgraduate and early career researchers in Australia. Tertiary Education and Management, 10:227-241. http://dx.doi.org/10.1080/13583883.2004.9967129

Wisker, G. (2008). The postgraduate research handbook. New York, USA: Palgrave MacMillan.

World Economic Forum. (2013). The Global Gender Gap Report 3:12-13. 